\title{
A Study on Cervical Cancer Screening Amongst Nurses in Lagos University Teaching Hospital, Lagos, Nigeria
}

\author{
O. Awodele • A. A. A. Adeyomoye • D. F. Awodele • \\ V. Kwashi $\cdot$ I. O. Awodele $\cdot$ D. C. Dolapo
}

Published online: 11 January 2011

(C) The Author(s) 2011. This article is published with open access at Springerlink.com

\begin{abstract}
Cancer of the cervix is the commonest genital tract malignancy in the female, and it has been ranked second to breast cancer. It has positive association with infection of human papillomavirus. Cervical cancer incidence and mortality have declined substantially in western countries following the introduction of screening programmes. This present study investigated the knowledge, attitude and practice of nurses in Lagos University Teaching Hospital (LUTH) towards cervical cancer screening as they are important health personnel that are suppose to educate women on the need for cervical cancer screening. The study is a descriptive cross-sectional survey
\end{abstract}

O. Awodele ( $\square)$

Department of Pharmacology, College of Medicine,

University of Lagos,

Lagos, Nigeria

e-mail: awodeleo@yahoo.com

A. A. A. Adeyomoye

Department of Radiation Biology, Radiodiagnosis and

Radiotherapy, College of Medicine, University of Lagos,

Lagos, Nigeria

D. F. Awodele

School of Midwifery, Lagos University Teaching Hospital,

Lagos, Nigeria

V. Kwashi

School of Health Information Management,

Lagos University Teaching Hospital,

Lagos, Nigeria

I. O. Awodele

Babcock University Medical Centre,

Ilishon Remon, Ogun State, Nigeria

D. C. Dolapo

Department of Community Health,

Lagos University Teaching Hospital,

Lagos, Nigeria of the knowledge, attitude and practice of 200 nurses in LUTH towards cervical cancer screening. The results obtained showed that $99 \%$ of the respondents were aware of cervical cancer and that $92 \%$ of the respondents were also aware of the causative organism of cervical cancer (human papillomavirus). Their major sources of information were through electronic media $(43.9 \%)$ and health professionals $(37.4 \%)$. Furthermore, the respondents were quiet aware of Pap smear (91\%) as one of the screening techniques of cervical cancer and had good attitudes (89\%) towards Pap smear, but most of them had never done it before. The study further revealed that majority of the respondents did not know colposcopy as one of the screening techniques for cervical cancer. Finally, it has been made known from this study that nurses have good knowledge of cervical cancer but have limited understanding of the types of cervical cancer screening techniques and poor disposition towards undergoing cervical cancer screening. It may thus be recommended that institutions should periodically organise seminars and training for health personnel especially the nurses which form a group of professionals that should give health education to women about cervical cancer. This training may be done as part of the orientation programme to newly employed staff.

Keywords Cervical cancer Pap smear · Nurses · Screening techniques

\section{Introduction}

Cancer is responsible for about 51 million deaths yearly, out of which cervical cancer accounts for $8.5 \%$, most of which occurred in the developing countries. About half a million new cases are seen worldwide each year, most occurring in developing countries [1]. Cancer of the cervix is the commonest genital tract malignancy in the female [2]. 
It has been ranked second to breast cancer in the reports of $[3,4]$. Cervical cancer has positive association with infection of human papillomavirus (HPV), and repeated or persistent HPV infections appear to raise the chances of developing the disease [5].

The work of Muñoz et al. [6] has shown that tobacco smoking, high parity, long-term hormonal contraceptive use, co-infection with Chlamydia trachomatis, herpes simplex virus type 2, HIV, immunosuppression, certain dietary deficiencies, and genetic and immunological host factors are contributing factors to cervical cancers.

The availability of effective prophylactic HPV vaccines gives new promise for a primary prevention strategy for HPV infection and cervical cancer [7]. However, the current vaccines only protect against $70 \%$ of the disease, and are only effective for those not yet exposed to the virus.

Cervical cancer incidence and mortality have declined substantially in western countries following the introduction of screening programmes. Screening programmes in Africa are however often rudimentary or nonexistent. The screening techniques often used are Pap smear test [8], visual inspection of the acetic acid-painted cervix (VIA) [9], cryotherapy for moderate cervical dysplasia [9] and HPV DNA test [10].

The earlier reports of [11-13] have respectively shown that less than $10 \%$ of the women in Maiduguri are aware of cervical cancer and its symptoms, inadequate knowledge of aetiology and prevention of cervical cancer among nurses in Ibadan, and $52.8 \%$ awareness of cervical cancer screening methods among women in Owerri.

Lack of knowledge of cancer screening exercise may be a reflection of general poor health education in the country. Therefore, comprehensive health education programmes are more likely to be beneficial than disease-specific programmes in tackling this problem.

The present study intends to investigate the knowledge, attitude and practice of nurses in Lagos University Teaching Hospital towards cervical cancer screening as they are important health personnel that are suppose to educate women on the need for cervical cancer screening.

\section{Methodology}

Description of the Study Area

Lagos University Teaching Hospital is one of the largest teaching hospitals in Nigeria. It is located in Lagos State which is a state in southwestern Nigeria. Lagos is one of Nigeria's most populated states. It is the chief port, principal economic and cultural centre. The teaching hospital has 761 bed spaces and records over 9,000 $(\approx 10,000)$ patient attendances in a month. There are about 641 nurses working in Lagos University Teaching Hospital (LUTH) in all departments.

Study Population

The study population includes all the 641 nurses working in Lagos University Teaching Hospital, Lagos.

\section{Study Design}

This study is a descriptive cross-sectional survey of cervical cancer screening amongst 200 nurses in Lagos University Teaching Hospital, Lagos, Nigeria.

\section{Sample Size Determination}

A sample size of approximately 200 was calculated using Fischer formula. The sample size was increased to 250 in order to give allowance for nonresponse. However, 200 questionnaires were retrieved after the study.

\section{Sampling Method}

A systematic random sampling technique was employed to select one out of every three nurses in the different wards, theatres and clinics.

\section{Data Collection}

Data were collected using a standard closed-ended structured questionnaire adopted from WHO with three sections on sociodemography, knowledge on cervical cancer and attitude towards cervical cancer screening. The subjects were mainly not required to write but just to tick the appropriate boxes which were provided for each option given. Names were not used for identification, but coding numbers were used instead.

\section{Data Analysis}

The 200 questionnaires obtained from the study were analysed using the EPI-INFO 2002 software programme. The data were presented in frequency distribution tables with percentages, and chi-square analysis was used to test the significance at $p<0.05$.

\section{Results}

The results obtained showed nurses in LUTH to have highest (38.5\%) age range between 20 and 29 years and lowest age $(6 \%)$ greater or equal to 50 years. Of the respondents, $55.0 \%$ (110) were married, while 79 (39.5\%) 
Table 1 Sociodemographic variable

\begin{tabular}{|c|c|c|}
\hline Variable & Frequency $(n=200)$ & Percent \\
\hline \multicolumn{3}{|l|}{ Age (year) } \\
\hline $20-29$ & 77 & 38.5 \\
\hline $30-39$ & 72 & 36.0 \\
\hline $40-49$ & 39 & 19.5 \\
\hline$\geq 50$ & 12 & 6.0 \\
\hline Total & 200 & 100 \\
\hline \multicolumn{3}{|l|}{ Marital status } \\
\hline Single & 79 & 39.5 \\
\hline Married & 110 & 55.0 \\
\hline Divorced/separated & 6 & 3.0 \\
\hline Widowed & 5 & 2.5 \\
\hline Total & 200 & 100 \\
\hline \multicolumn{3}{|l|}{ Ethnicity } \\
\hline Hausa & 7 & 3.5 \\
\hline Igbo & 50 & 25.0 \\
\hline Yoruba & 138 & 69.0 \\
\hline Others & 5 & 2.5 \\
\hline Total & 200 & 100 \\
\hline \multicolumn{3}{|l|}{ Religion } \\
\hline Christianity & 170 & 85.0 \\
\hline Islam & 30 & 15.0 \\
\hline Total & 200 & 100 \\
\hline \multicolumn{3}{|l|}{ Age at first intercourse (year) } \\
\hline$<20$ & 20 & 10.0 \\
\hline $20-24$ & 66 & 33.0 \\
\hline $25-29$ & 88 & 44.0 \\
\hline$\geq 30$ & 26 & 13.0 \\
\hline Total & 200 & 100 \\
\hline Mean age at first intercourse & $24.8 \pm 4.8$ & \\
\hline
\end{tabular}

Fig. 1 Awareness of cervical cancer and human papillomavirus among nurses $(n=200)$

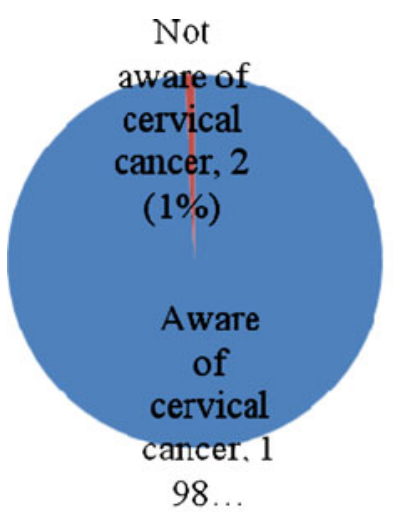

Not

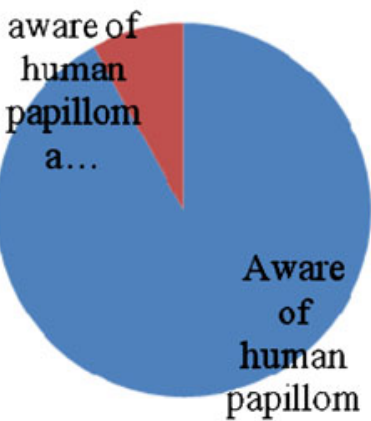

a...

Fig. 2 Awareness of Pap smear and uptake of Pap smear and VIA among nurses $(n=200)$
Table 2 Sources of information about cervical cancer

\begin{tabular}{llr}
\hline Source of information & Frequency $(n=198)$ & Percent \\
\hline Electronic media & 87 & 43.9 \\
Print media & 33 & 16.7 \\
Health professionals & 74 & 37.4 \\
School seminars & 62 & 31.3 \\
Friends and relatives & 33 & 16.7 \\
Church/mosque & 15 & 7.6 \\
Bills/posters & 32 & 16.2 \\
Journals & 51 & 25.8 \\
\hline
\end{tabular}

Multiple responses are given 
were single. The tribe with highest distribution was Yoruba $(69.0 \%)$ and Igbo $(25.0 \%)$, and $3.5 \%$ of the nurses were of Hausa tribe. Christianity $(85 \%)$ was the major religion of the respondents (Table 1).

Table 2 revealed the sources of information about cervical cancer. The results showed that the highest proportion of the respondents got the information about cervical cancer from electronic media (43.9\%). The other sources are health professionals $(37.4 \%)$, school seminars $(31.3 \%)$ and journals $(25.8 \%)$, and the lowest proportion of the respondents got their information from church/mosque $(7.6 \%)$.

The results in Fig. 1 showed that $99 \%$ of the respondents were aware of cervical cancer, while $92 \%$ of the respond- ents were aware of the causative organism of cervical cancer (human papillomavirus). Figure 2 further showed that $182(91 \%)$ of the respondents were aware of Pap smear; however, $159(79.5 \%)$ and $175(87.5 \%)$ of the respondents have never done Pap smear and visual inspection with acetic acid, respectively.

Table 3 showed the respondents' comprehensive knowledge of cervical cancer. Of the respondents, $54 \%$ associated cervical cancer with having multiple sexual partners, and $47.5 \%$ linked cervical cancer with having sex at early age, while $52 \%$ of the respondents understood human papillomavirus to be a causative agent in cervical cancer. However, $18.5 \%$ and $19.5 \%$ of the respondents felt that excess alcohol and smoking could cause cervical cancer,

Table 3 Knowledge of cervical cancer

\begin{tabular}{|c|c|c|}
\hline & Frequency $(n=200)$ & Percent \\
\hline \multicolumn{3}{|l|}{ Causes of cervical cancer ${ }^{\mathrm{a}}$} \\
\hline Excess alcohol & 37 & 18.5 \\
\hline Having sexual partner & 108 & 54.0 \\
\hline Witchcraft & 8 & 4.0 \\
\hline Having sex at early age & 95 & 47.5 \\
\hline Use of oral contraceptive & 49 & 24.5 \\
\hline Smoking & 39 & 19.5 \\
\hline Human papillomavirus infection & 104 & 52.0 \\
\hline Family history of cervical cancer & 40 & 20.0 \\
\hline \multicolumn{3}{|l|}{ Signs of cervical cancer } \\
\hline Dysmenorrhoea & 25 & 12.5 \\
\hline Menorrhagia during teenage years (DTY) & 18 & 9.0 \\
\hline Postcoital bleeding & 32 & 16.0 \\
\hline Postmenopausal bleeding (PMB) & 38 & 19.0 \\
\hline Foul-smelling discharge from the vaginal (FSDPV) & 55 & 27.5 \\
\hline Dysmenorrhoea and FSDPV & 3 & 1.5 \\
\hline Postcoital bleeding and FSDPV & 5 & 2.5 \\
\hline Dysmenorrhoea, postcoital bleeding and FSDPV & 5 & 2.5 \\
\hline Menorrhagia DTY, postcoital bleeding, PMB and FSDPV & 8 & 4.0 \\
\hline Do not know & 11 & 5.5 \\
\hline Total & 200 & 100 \\
\hline \multicolumn{3}{|l|}{ Screening techniques for cervical cancer } \\
\hline Pap smear & 103 & 51.5 \\
\hline Testing for HPV & 21 & 10.5 \\
\hline Visual inspection with acetic acid (VIA) & 20 & 10.0 \\
\hline Colposcopy & 7 & 3.5 \\
\hline Pap smear and testing for HPV & 12 & 6.0 \\
\hline Pap smear and VIA & 11 & 5.5 \\
\hline Pap smear, testing for HPV and VIA & 26 & 13.0 \\
\hline Total & 200 & 100 \\
\hline \multicolumn{3}{|l|}{ Prevention of cervical cancer ${ }^{a}$} \\
\hline It is preventable & 171 & 85.5 \\
\hline It is possible to detect it & 190 & 95.0 \\
\hline Early detection can increase chance of survival & 163 & 81.5 \\
\hline
\end{tabular}


Table 4 Knowledge of uses of Pap smear and meaning of positive Pap smear result
Frequency $(n=200)$

Percent

\begin{tabular}{llr}
\hline Use of Pap smear & & \\
Detection of sexually transmitted diseases & 10 & 5.0 \\
Detection of human papillomavirus infection & 2 & 1.0 \\
Detection of precancerous state of cervical cancer & 120 & 60.0 \\
Cure of cervical cancer & 12 & 6.0 \\
Prevention of cervical cancer & 37 & 18.5 \\
Do not know & 19 & 9.5 \\
Total & 200 & 100 \\
Meaning of positive Pap smear result & & 34.5 \\
Full-blown cancer of cervix & 69 & 59.0 \\
Cervical cancer that is about to start & 118 & 2.5 \\
Cancer of the breast & 5 & 4.0 \\
I do not know & 8 & 100 \\
Total & 200 & \\
How often should Pap smear be done & & 54.0 \\
At least once in a year & 108 & 11.5 \\
At least once in 2 years & 23 & 2.5 \\
At least once in 3 years & 5 & 13.5 \\
At least once in a lifetime & 27 & 18.5 \\
Do not know & 37 & 100 \\
Total & 200 & 26.5 \\
Who should have Pap smear done & & 100 \\
Women of all age & 52 & 29.5 \\
Women that are still giving birth & 29 & 34.0 \\
Women that are 18 years and above & 68 & \\
Women above 65 years of age & 200 & \\
Do not know & & \\
Total & & \\
\hline & & \\
\hline
\end{tabular}

respectively. Almost all the respondents (85.5\%) were aware of the preventability and detectability (95\%) of cervical cancer. The results further showed a good understanding of the signs of cervical cancer and the various screening techniques.

The findings in Table 4 showed the knowledge of the uses of Pap smear and the meaning of positive Pap smear results. Of the respondents, 60\% (120) understood that Pap smear could be used to detect precancerous state of cervical cancer, while $18.5 \%$ (37) respondents felt Pap smear could be used to prevent cervical cancer. Moreover, 59\% (118) of the respondents knew that the positive results of Pap smear meant that cervical cancer is about to start, while $34.5 \%$ (69) of the respondents felt that the positive results of cervical cancer meant full-blown cervical cancer. The results further showed that $54 \%$ (108) of the respondents knew that Pap smear should be done once in a year, while $11.5 \%$ (23), 2.5\% (5) and 13.5\% (27) felt that it should be done once in 2 years, 3 years and lifetime, respectively. Of the respondents, $18.5 \%$ (37) did not know the uses of Pap smear. A poor response of 68 (34\%) of the respondents felt that women above 65 years of age should have Pap smear done.

Figure 3 results showed good attitude of nurses towards Pap smear. Of the respondents, 89\% thought that it is advisable to have Pap smear done, and $34 \%$ of the

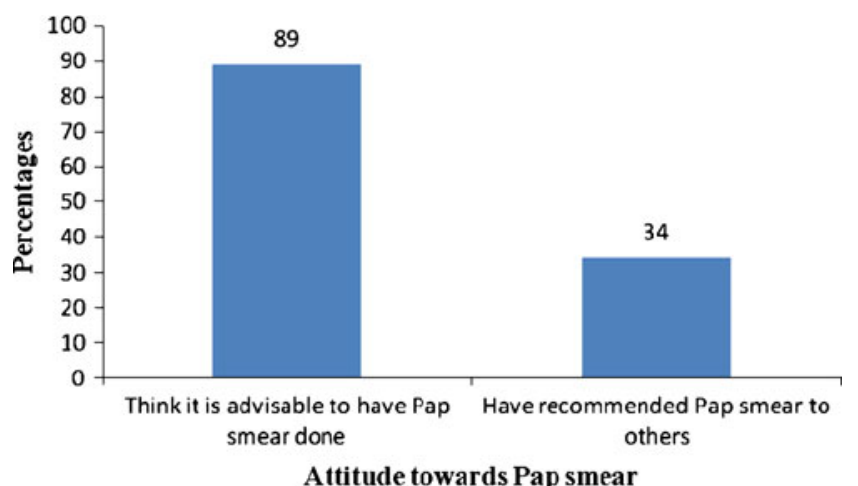

Fig. 3 Attitude of nurses towards Pap smear $(n=200)$ 
Table 5 Reasons for not doing Pap smear and for not recommending it to others
Table 6 Associations between sociodemographic variables and awareness of Pap smear

\begin{tabular}{llr}
\hline Variable & Frequency & Percent \\
\hline Reasons for not doing Pap smear $(n=159)$ & & 9.4 \\
No time & 15 & 11.9 \\
No money & 19 & 23.9 \\
Not thought about it & 38 & 8.2 \\
Still young for it & 13 & 17.0 \\
It is costly & 27 & 1.3 \\
Not aware of any test & 2 & 5.7 \\
Do not know where the test is done & 9 & 5.0 \\
Others & 8 & 17.6 \\
No reason & 28 & 100 \\
Total & 159 & \\
Reasons for not recommending Pap smear to others $(n=132)$ & & 9.8 \\
Females below 20 years are safe from cervical cancer & 13 & 14.4 \\
Pap smear is painful & 19 & 5.3 \\
Pap smear test could be dangerous and risky & 7 & 24.2 \\
Others & 32 & 46.2 \\
No reason & 61 & 100 \\
Total & 132 & \\
\hline
\end{tabular}

\begin{tabular}{|c|c|c|c|c|c|c|}
\hline \multirow[t]{2}{*}{ Variable } & \multicolumn{3}{|c|}{ Aware of Pap smear (\%) } & \multirow[t]{2}{*}{$\chi^{2}$} & \multirow[t]{2}{*}{$d f$} & \multirow[t]{2}{*}{$p$} \\
\hline & Yes & No & Total & & & \\
\hline \multicolumn{7}{|l|}{ Age (year) } \\
\hline $20-29$ & $60(77.9)$ & $17(22.1)$ & 77 & 26.22 & 3 & 0.00 \\
\hline $30-39$ & $71(98.6)$ & $1(1.4)$ & 72 & & & \\
\hline $40-49$ & $39(100)$ & $0(0)$ & 39 & & & \\
\hline$\geq 50$ & $12(100)$ & $0(0)$ & 12 & & & \\
\hline \multicolumn{7}{|l|}{ Marital status } \\
\hline Single & $63(79.7)$ & $16(20.3)$ & 79 & 20.23 & 3 & 0.0002 \\
\hline Married & $108(98.2)$ & $2(1.8)$ & 110 & & & \\
\hline Divorced/separated & $6(100)$ & $0(0)$ & 6 & & & \\
\hline Widowed & $5(100)$ & $0(0)$ & 5 & & & \\
\hline \multicolumn{7}{|l|}{ Ethnicity } \\
\hline Hausa & $7(100)$ & $0(0)$ & 7 & 1.51 & 3 & 0.60 \\
\hline Igbo & $45(90.0)$ & $5(10.0)$ & 50 & & & \\
\hline Yoruba & $126(91.3)$ & $12(8.7)$ & 138 & & & \\
\hline Others & $4(80.0)$ & $1(20.0)$ & 5 & & & \\
\hline \multicolumn{7}{|l|}{ Religion } \\
\hline Christianity & $153(90.0)$ & $17(10.0)$ & 170 & 1.38 & 1 & 0.21 \\
\hline Islam & $29(96.7)$ & $1(3.3)$ & 30 & & & \\
\hline \multicolumn{7}{|c|}{ Age at first intercourse (year) } \\
\hline$<20$ & $19(95.0)$ & $1(5.0)$ & 20 & 4.24 & 3 & 0.34 \\
\hline $20-24$ & $62(93.9)$ & $4(6.1)$ & 66 & & & \\
\hline $25-29$ & $76(86.4)$ & $12(13.6)$ & 88 & & & \\
\hline$\geq 30$ & $25(96.2)$ & $1(3.8)$ & 26 & & & \\
\hline
\end{tabular}


respondents have recommended Pap smear to others. The results in Table 5 showed that $17 \%$ (27) of the respondents did not do Pap smear because it is costly, and $11.9 \%$ (19) claimed not to have money. The respondents did not recommend Pap smear for people because it is painful $(14.4 \%)$ and risky (5.3\%).

The results in Tables 6 and 7 showed a significant $(p \leq$ 0.05 ) association between age, marital status, and awareness of Pap smear and uptake of Pap smear, respectively.

\section{Discussion}

At every stage in life, a woman in the third world risks some serious health problems. These include HIV/AIDS, high maternal mortality rates, and cancer of the cervix later in life. Cancer of the cervix is a preventable disease, and a key aspect of its prevention is the detection of the premalignant form by cervical screening [13]

This present study has shown that nurses are aware of cervical cancer (99\%) which is consistent with the earlier study of [13]. It also corroborates the reports of [14] that showed a good association between level of education and cervical cancer awareness. The major sources of information about cervical screening as revealed in this study were through electronic media and health professionals. But it is a thing of concern that information about cervical cancer is poorly disseminated in churches and mosque (7.6\%). It may be important that churches and mosques begin to have a forum to discuss health issues as information obtained from these spiritual institutions are usually taken serious.

Though the respondents have good knowledge of the causes and signs of cervical cancer, a few proportions (18.5\%) felt that excess intake of alcohol could cause the disease. The respondents are quiet aware of Pap smear (91\%) as one of the screening techniques of cervical cancer and have good attitudes (89\%) towards Pap smear, but most of them have never done it before. The extremely low percentage $(12 \%)$ of the respondents above 50 years who have done Pap smear is consistent with the studies of [14, 15] that showed a good correlation between old age and low Pap smear testing. Quite sizable percentage (18.5\%) of the respondent thought that Pap smear is used to prevent cervical cancer and that Pap smear should be done once in a lifetime. The study further revealed a majority of the respondents not to know colposcopy as one of the screening techniques for cervical cancer. These wrong opinions may necessitate institutional-based workshop and training on cervical cancer and other diseases so as to give people good knowledge of the disease.
Table 7 Associations between sociodemographic variables and uptake of Pap smear

\begin{tabular}{|c|c|c|c|c|c|c|}
\hline \multirow[t]{2}{*}{ Variable } & \multicolumn{3}{|c|}{ Have done Pap smear (\%) } & \multirow[t]{2}{*}{$\chi^{2}$} & \multirow[t]{2}{*}{$d f$} & \multirow[t]{2}{*}{$p$} \\
\hline & Yes & No & Total & & & \\
\hline \multicolumn{7}{|l|}{ Age (year) } \\
\hline $20-29$ & $9(11.7)$ & $68(88.3)$ & 77 & \multirow[t]{4}{*}{24.51} & \multirow[t]{4}{*}{3} & \multirow[t]{4}{*}{0.0001} \\
\hline $30-39$ & $11(15.3)$ & $61(84.7)$ & 72 & & & \\
\hline $40-49$ & $13(33.3)$ & $26(66.7)$ & 39 & & & \\
\hline$\geq 50$ & $8(66.7)$ & $4(33.3)$ & 12 & & & \\
\hline \multicolumn{7}{|l|}{ Marital status } \\
\hline Single & $6(7.6)$ & $73(92.4)$ & 79 & \multirow[t]{4}{*}{13.83} & \multirow[t]{4}{*}{3} & \multirow[t]{4}{*}{0.001} \\
\hline Married & $31(28.2)$ & $79(71.8)$ & 110 & & & \\
\hline Divorced/separated & $2(33.3)$ & $4(66.7)$ & 6 & & & \\
\hline Widowed & $2(40.0)$ & $3(60.0)$ & 5 & & & \\
\hline \multicolumn{7}{|l|}{ Ethnicity } \\
\hline Hausa & $3(42.9)$ & $4(57.1)$ & 7 & \multirow[t]{4}{*}{3.65} & \multirow[t]{4}{*}{3} & \multirow[t]{4}{*}{0.32} \\
\hline Igbo & $9(18.0)$ & $41(82.0)$ & 50 & & & \\
\hline Yoruba & $29(21.0)$ & $109(79.0)$ & 138 & & & \\
\hline Others & $0(0)$ & $5(100)$ & 5 & & & \\
\hline \multicolumn{7}{|l|}{ Religion } \\
\hline Christianity & $27(15.9)$ & $143(84.1)$ & 170 & \multirow[t]{2}{*}{14.83} & \multirow[t]{2}{*}{1} & \multirow[t]{2}{*}{0.0003} \\
\hline Islam & $14(46.7)$ & $16(53.3)$ & 30 & & & \\
\hline \multicolumn{7}{|c|}{ Age at first intercourse (year) } \\
\hline$<20$ & $5(25.0)$ & $15(75.0)$ & 20 & \multirow[t]{4}{*}{2.87} & \multirow[t]{4}{*}{3} & \multirow[t]{4}{*}{0.57} \\
\hline $20-24$ & $9(13.6)$ & $57(86.4)$ & 66 & & & \\
\hline $25-29$ & $21(23.9)$ & $67(76.1)$ & 88 & & & \\
\hline$\geq 30$ & $6(23.1)$ & $20(76.9)$ & 26 & & & \\
\hline
\end{tabular}


The findings from this study showed that some respondents $(17 \%)$ did not do Pap smear because it is costly. This observation is consistent with the work of [16] that showed that socioeconomic status played important role in the demand for cervical cancer screening. Women should be on health insurance programmes so as to encourage them to regularly undergo this examination as earlier recommended by [17]. This present study further revealed that there are significant associations $(p \leq 0.05)$ between age of respondents, marital status, and awareness and uptake of cervical cancer screening. This assertion may be justified by the fact that married people of reproductive age are more susceptible to cervical cancer than older married people who have passed the reproductive age.

Finally, it has been made known from this study that nurses have good knowledge of cervical cancer but have limited understanding of the types of cervical cancer screening techniques and poor disposition towards undergoing cervical cancer screening. It may thus be recommended that institutions should periodically organise seminars and training for health personnel especially the nurses which form a group of professionals that can give health education to women about cervical cancer. This training may be done as part of the orientation programme to newly employed staff. Moreover, hospital-based pro-screening campaign is highly advocated so as to enhance prevention of cervical cancer.

Open Access This article is distributed under the terms of the Creative Commons Attribution Noncommercial License which permits any noncommercial use, distribution, and reproduction in any medium, provided the original author(s) and source are credited.

\section{References}

1. Jimoh AS, Abdul IF (2004) A review of one hundred and three (103) histologically confirmed cases of carcinoma of the cervix at the University of Ilorin Teaching Hospital Nigeria. Niger Med Pract 45:55-60
2. Adefuye PO (2006) Knowledge and practice of cervical cancer screening among female professional health workers in a suburban district of Nigeria. Niger Med Pract 50(1):19-22

3. Adebamowo CA, Ajayi OO (2000) Breast cancer in Nigeria. West Afr J Med 19:179-194

4. Madong BM, Madaka AKJ, Mannaseh AN (2003) Malignant disease in Jos: a follow up. Ann Afr Med 2:48-53

5. Bosch FX, Lorincz AT, Munoz N, Meijer CJ, Shah KV (2002) The causal relation between human papillomavirus and cervical cancer. J Clin Pathol 55:244-265

6. Muñoz N, Bosch FX, de Sanjosé S (2006) The causal link between human papillomavirus and invasive cervical cancer: a population-based case-control study. Int J Cancer 119(5):11081124

7. Schiller JT, Castellsagu X, Villa LL, Hildesheim A (2008) An update of prophylactic human papillomavirus L1 virus-like particle vaccine clinical trial results. Vaccine 26(Suppl 10):K53K61

8. Redmond O'Neal (2009) Cancer-stricken Farrah Fawcett weighs 86 pounds: Redmond O'Neal www.thaindian.com/.../cancer-strickenfarrah-fawcett-weighs-86-pounds-redmond-oneal_100181396.html USA

9. IARC (2003) Hand book on cancer. www.iarc.fr/en/media-centre/ $\mathrm{pr} / 2003 / \mathrm{index}$

10. Dillner J, Rebolj M, Birembaut P, Petry KU, Szarewski A, Munk C, de Sanjose S, Naucler P, Lloveras B, Kjaer S, Cuzick J, van Ballegooijen M, Clavel C, Iftner T (2008) Long term predictive values of cytology and human papillomavirus testing in cervical cancer screening: joint European cohort study. BMJ 337:a1754

11. Audu BM, El-Nafaty AU, Khalil M, Otubu JAM (1999) Knowledge and attitude of cervical cancer screening among women in Maiduguri. J Obstet Gynaecol 19(3):295-297

12. Ayinde OA, Omigodun AO (2003) Knowledge, attitude and practices related to prevention of cancer of the cervix among female health workers in Ibadan. J Obstet Gynaecol 23(1):59-62

13. Ezem BU (2007) Awareness and uptake of cervical cancer screening in Owerri, South-Eastern Nigeria. Ann Afr Med 6 (3):94-98

14. Mandelblatt JS (1999) Is HIV infection a cofactor for cervical squamous cell neoplasia? Cancer Epidemiol Biomark Prev 8:97106

15. Wang PD, Lin RS (1996) Sociodemographic factors of Pap smear screening in Taiwan. Public Health 110(2):123-127

16. Wang PD (2005) Acceptance of Pap smear testing. In: Chapter two of theoretical framework. Nccur.lib.nccu.du.tw/bitstream

17. Rodriguez WR, Christodoulides N, Floriano PN, Graham S, Mohanty S (2005) A microchip CD4 counting method for HIV monitoring in resource-poor settings. PLoS Med 2(7):e182 